\title{
MOOC construction and application in professional degree postgraduate education: taking Introduction to Engineering Optics as an example
}

Feng Hu, Jin-peng Zhou, Xing-shu Wang

Feng Hu, Jin-peng Zhou, Xing-shu Wang, "MOOC construction and application in professional degree postgraduate education: taking Introduction to Engineering Optics as an example," Proc. SPIE 10452, 14th Conference on Education and Training in Optics and Photonics: ETOP 2017, 1045256 (16 August 2017); doi: 10.1117/12.2269679

SPIE Event: 14th Conference on Education and Training in Optics and Photonics, ETOP 2017, 2017, Hangzhou, China 


\title{
MOOC Construction and Application in Professional Degree Postgraduate Education: Taking Introduction to Engineering Optics as an Example
}

\author{
Hu Feng*, Zhou Jin-peng, Wang Xing-shu \\ College of Opto-Electronic Science and Engineering, National University of Defense Technology, \\ Changsha 410073, China
}

\begin{abstract}
Aiming at the deficiency of the traditional postgraduate education mode for professional degree, such as the conflict between work and study, restricted supply and demand and poor efficiency of course teaching, the emergence of Massive Open Online Course (MOOC) which has large scale, online and open features can make up for the shortage of traditional professional degree postgraduate education mode by introducing MOOC teaching mode. However, it is still a fangle to integrate MOOC into the traditional postgraduate education for professional degree and there are no standard methods for reference in the construction of MOOC courses as well as the corresponding evaluations. In this paper, the construction method and practical experience of MOOC courses for professional degree postgraduate education are discussed in details, based on the MOOC course of Introduction to Engineering Optics. Firstly, the principle of MOOC course contents for professional degree postgraduate education is introduced from the aspects of students' demand, MOOC features and practical applications. Secondly, the optimization of MOOC teaching mode is discussed in order to improve the teaching quality and learning efficiency. Thirdly, in order to overcome the deficiency of current MOOC examination schemes, a novel MOOC evaluation scheme is proposed which is capable of assessing students' learning attitude as well as their ability and performance differences. Finally, a practical summary is given about how to integrate the MOOC teaching mode into the postgraduate education for professional degree, including the constructions of teaching team, course system as well as other factors. From the paper, we can conclude that the integration of MOOC teaching mode into the postgraduate education for professional degree will improve the teaching quality and efficiency.
\end{abstract}

Keywords: Massive Open Online Course (MOOC), Professional Degree Postgraduate Education, Introduction to Engineering Optics

\section{INTRODUCTION}

Postgraduate education with professional degree is playing an important role in cultivating a number of high-quality professionals. With the development of this education mode, some disadvantages have emerged, such as conflict between work and study, restricted supply and demand and poor efficiency of course teaching. The rules of postgraduate education with professional degree requires that learners should attend courses in full time, which will affect their present work to some extent. In addition, the enrollment scale for the traditional postgraduate education with professional degree is limited, which cannot meet the education demand of candidates. Thirdly, in the teaching mode of traditional postgraduate education with professional degree, learners always obtain course contents passively and will not attend courses with high enthusiasm, which will affect the teaching quality.

The emergence of Massive Open Online Course (MOOC) which has large scale, online and open features ${ }^{1,2}$ can make up for the shortage of traditional professional degree postgraduate education mode by introducing MOOC teaching mode ${ }^{3}$. However, it is still a fangle to integrate MOOC into the traditional postgraduate education for professional degree and there are no standard methods for reference in the construction of MOOC courses as well as the corresponding evaluations. Therefore, further research and exploration need to be made in order to make MOOC teaching mode play a vital role in the postgraduate education for professional degree. In this paper, the construction method and practical

*hufeng683@163.com

14th Conference on Education and Training in Optics and Photonics: ETOP 2017, edited by Xu Liu,

Xi-Cheng Zhang, Proc. of SPIE Vol. 10452, 1045256 • ( 2017 ICO, IEEE, OSA, SPIE

CCC code: $0277-786 X / 17 / \$ 18 \cdot$ doi: $10.1117 / 12.2269679$ 
experiences of MOOC courses for professional degree postgraduate education are discussed in details, based on the MOOC course of Introduction to Engineering Optics. The paper will include the following contents. Firstly, the principle of MOOC course contents for professional degree postgraduate education is introduced from the aspects of students' demand, MOOC features and practical applications. Secondly, the optimization of MOOC teaching mode is discussed in order to improve the teaching quality and learning efficiency. Thirdly, in order to overcome the deficiency of current MOOC examination schemes, a novel MOOC evaluation scheme is proposed which is capable of assessing students' learning attitude as well as their ability and performance differences. Finally, a practical summary is given about how to integrate the MOOC teaching mode into the postgraduate education for professional degree, including the constructions of teaching team, course system as well as other factors.

\section{PRINCIPLES OF MOOC COURSE CONTENTS}

Different from the traditional class-based teaching mode for professional degree postgraduate education, the space and time of MOOC-based teaching mode will not be restricted and is more flexible. Therefore, it needs to rearrange the course contents based on the considerations below.

\subsection{Selecting course contents according to demands of attenders}

Learners who attend professional degree postgraduate education have work experience and have a deep understanding of professional knowledge needs and knowledge short board. They often attend courses with specific problems and hope the course contents can help them to solve practical problems in their work. Therefore, it needs to understand the learning needs of attenders and know their specific requirements of fields in which they are engaged, before making course contents. In addition, the characteristics of attenders and individual differences need to be considered. Different attenders have various knowledge levels and work experiences, which requires that the course contents should pay more attention to the universality, on the basis of technical considerations. Especially for science and engineering courses, the complicated theoretical formula derivations need to be reduced.

\subsection{Constructing knowledge modules of course based on MOOC characters}

Due to MOOC-based teaching mode in professional degree postgraduate education, the knowledge modules need to be constructed, combining the module character of MOOC in the premise of teaching contents. To this end, traditional course contents need to be rearranged and individual knowledge point should be selected which can be linked together to form a knowledge point tree.

\subsection{Making teaching cases in combination with practical application}

MOOC characters determine that attenders will complete course study actively, which requires that courses should be interesting. Teaching cases will play an important role in keeping course interest. Therefore, cases introduction should be made before starting actual course contents, which will make sure that learners' attention can be attracted in the first place so that they can complete course study better. In addition, teaching cases should be used to help learners understand how knowledge they have learned is employed to solve practical problems, after every chapter. By considering factors above, the course contents will be more practical, interesting and technical.

\section{OPTIMIZATION OF TEACHING MODE}

The simplification of traditional teaching mode and restriction of fixed teaching location have been overcome by introduced the MOOC mode in the professional degree postgraduate education and the course-taught diversity has been implemented. In the MOOC-based teaching, besides the video knowledge point, interactive teaching activities such as interesting question-and-answer and quiz will be introduced as well. In such case, learners will not study knowledge passively, but make themselves in the actual learning scene, which will improve the study effect greatly.

In order to enhance the teaching quality, the components of videos, quizzes and experimental demonstrations need to be arranged in a prober order so as to optimize the teaching mode. Taking 'Introduction to Engineering Optics' as an example, the teaching modules include knowledge videos, class tests, chapter quizzes, homework and self-study offline. Teaching cases will be introduced first to attract attenders' attention. Then interesting question-and-answer will be carried on so as to make attenders learn subsequent knowledge points with respective questions. In the video teaching, class tests are added and attenders must finish those tests before continuing next course study. After the course teaching of every chapter is completed, another teaching case will be given to guide attenders to solve practical problems using 
knowledge they have just learned. Finally, unit test and homework will be made to consolidate knowledge points. By adopting flexible teaching modes, attenders' learning enthusiasm and interest will be enhanced greatly.

\section{EVALUATION MECHANISM OF MOOC-BASED COURSE}

At present, MOOC-based teaching mode in the professional degree postgraduate education has played a key role in improving the teaching quality and attenders' learning enthusiasm. However, its major problem is how to evaluate attenders' learning quality effectively. Here we propose a novel evaluation mechanism of MOOC-based course--multiple-factor weighted mean. The evaluation mechanism includes class-test score, unit-test score, chapter-homework score, final-exam score, course-design score and class-behavior score. The class-test score can be obtained by accumulating all class-test scores and averaging. The unit-test score and chapter-homework score will be obtained by using the same method as the class-test score. The evaluation of chapter homework consists of interactive evaluation of course attenders and self-homework performance. The final exam is the same as current MOOC test which will be implemented online and its score can be given timely by computers. The final score of every attender will be obtained by multiplying scores of each component with the corresponding degree of difficulty and then averaging. The proposed evaluation mechanism combines class performance of attenders with their learning effect. Attenders who performance well and are active will obtain high performance score which is determined by their learning attitude. The learning effect and individual difference of attenders will be determined by course tests and designs which examine attenders' abilities of problem-solved using acquired knowledge. Therefore, the proposed evaluation mechanism can examine both the learning attitude of attenders and their ability difference so that the education quality of professional degree postgraduate education can be guaranteed.

\section{SUMMARY OF MOOC-BASED PROFESSIONAL DEGREE POSTGRADUATE EDUCATION PRACTICE}

From our MOOC-based professional degree postgraduate education practice, the factors below should be considered as well, besides the discussions above. One is to strengthen the construction of teaching team. Different from traditional teaching mode, the MOOC-based teaching mode includes many components such as establishments of course contents, video records and online maintenance and so on. Therefore, a teaching team in which each person has his own task needs to be built in the course construction. Secondly, the course system construction should be emphasized on. The professional degree postgraduate education will be supported by a number of courses. Therefore, the relationship between different courses needs to be considered as well in the course construction, besides the subject demands, which will avoid contents repetition and make attenders learn subsequent courses easily. Thirdly, the MOOC-based course teaching in professional degree postgraduate education should be different from traditional video teaching which lacks of interactive learning.

From the paper, we can conclude that the integration of MOOC teaching mode into the postgraduate education for professional degree will improve the teaching quality and efficiency. However, it is still a new thing to integrate MOOC mode into professional degree postgraduate education and further research needs to be made so as to obtain completed principles of course construction.

\section{REFERENCES}

[1] Li, M.L.. "Exploring the Instructional Design Principles of MOOCs," TSINGHUA JOURNAL OF EDUCATION.34(4),13-21(2013).

[2] Chen, X. G. and Wang D.M." On the Development Process and Main Characteristic of MOOC," Modern Educational Technology. 23,5-10(2013).Davis, A. R., Bush, C., Harvey, J. C. and Foley, M. F., "Fresnel lenses in rear projection displays," SID Int. Symp. Digest Tech. Papers 32(1), 934-937 (2001).

[3] Zhu, R.Q., Sun, D.Y., Li, Z. F., et al." Research on the MOOC Teaching Operation for Military Professional Degree Postgraduates: Taking NUDT as an Example," Journal of Higher Education Research. 39(2),4954(2016). 